\title{
Vascular catastrophe following the Dandy McKenzie operation for spasmodic torticollis
}

\author{
CBT ADAMS \\ From the Department of Neurological Surgery, Radcliffe Infirmary, Oxford, UK
}

SUMMARY Delayed brain stem ischaemia following operation for spasmodic torticollis, is described. The mechanism for this catastrophe is considered and a hypothesis proposed which might allow its prediction and prevention. The overall results, the side and complications of this operation are summarised.

A single case report of a catastrophic event deserves to be reported, particularly if such an event is as inexplicable as it was unexpected. Scoville and Bettis ${ }^{1}$ reported a similar, yet not identical, occurence. It is hoped that careful description of this case might help to produce some further understanding of the underlying mechanism.

\section{Case report}

The patient, a married lady born in 1926, had an uneventful life until 1966 when she developed a stiff neck soon to be followed by jerking of the chin to the left. Spasmodic torticollis was diagnosed. Radiograph of the cervical spine showed some mild spondylosis. A myelogram was normal. Local anaesthetic and alcohol injections into the right sternomastoid muscle provided temporary relief. Active extension of the neck relaxed the right sternomastoid muscle and so she was taught such exercises without obvious benefit. Apart from the embarrassment the patient found this condition was unpleasantly painful. For no known reason it improved in 1969 so that she had little or no pain and the deformity caused no embarrassment to her, although her family doctor commented that this was still apparent to him. Unfortunately, this satisfactory state persisted for only two years and in 1971 recurrance of pain and deformity caused the abrupt abandonment of a family summer holiday. Over the next two years the spasmodic torticollis became more obtrusive despite treatment with nitrazepam, haloperidol, diazepam, dimethothiazine, myanesin and propranolol. No abnormality of vestibular function was found, nor any significant psychiatric aetiological factors. By 1973 the relentless progression caused very severe and intractible depression such that her family doctor noted concern about possible suicide. In Sep-

Address for reprint requests: CBT Adams, Department of Neuro logical Surgery, Radcliffe Infirmary, Oxford OX2 6HE, UK

Received 12 March 1984

Accepted 17 March 1984 tember 1973 she was referred to Mr John Potter who noted that the torticollis was no longer spasmodic but had, for the previous six months, been a persistent deformity with the chin rotated to the left. All muscle groups were involved, but the right sternomastoid was particularly contracted. After full discussion with the patient, her husband and medical advisers, the patient underwent a Dandy McKenzie operation on the 11 January 1974. Even under anaesthesia the deformity of the neck persisted. A laminectomy from $\mathrm{C} 1-4$ was performed and the anterior roots of $\mathrm{C} 1, \mathrm{C} 2$ and $\mathrm{C} 3$ were sectioned bilaterally, together with intradural section of the right spinal accessory nerve. It was necessary to coagulate small arterial branches running with the right $\mathrm{C} 1$ and $\mathrm{C} 3$ roots. There was some troublesome bleeding near the origin of one of the upper rootlets of the right spinal accessory nerve. During the operation, which
was done in the sitting position, there was no drop in the systemic blood pressure or concern about air embolism. The patient was extubated, transferred to the recovery room and was seen to be responding normally to painful stimulation in all four limbs. About one hour after the end of the anaesthetic she suddenly became decerebrate with transient fixed dilated pupils, conjugate deviation of the eyes to the right and a mild rise of blood pressure. At no time did she stop breathing. Faced with this curious and inexplicable clinical picture it was decided to re-open the neck wound to be sure there was no haematoma, (CBTA). No significant clot or other abnormality was found.

Following this operation she breathed spontaneously, but remained unconscious. That evening all limbs were spastic with brisk reflexes and extensor plantar responses. The pupils reacted to light. Over the next two weeks she gradually regained consciousness. She developed a chest infection and on 16 January underwent a tracheostomy to clear the bronchi. During this period her legs remained spastic but her arms on occasions were noted to be flaccid. Her ability to cough and swallow persisted throughout this period, although possibly not completely normally.

By mid February the tracheostomy tube was removed. There was a spastic tetraparesis of all four limbs, including the shoulder girdles, but she was coughing and swallowing 
normally. Some weakness of eye closure was noted and there was a spastic dysarthria. Unfortunately this state has persisted. She can just move her right hand but is unable to move her legs or left arm. Sensation is quite unaffected, but her bladder and bowels do not function normally. She requires considerable help in all activities.

\section{Discussion}

The sudden onset and subsequent but incomplete improvement of the features described in this patient suggest an impairment of blood flow to the brain stem. The fact that respiration was unaffected despite severe tetraparesis suggests that the upper cervical cord (down to the $\mathrm{C} 4$ level) and the medulla oblongata were unaffected. Moreover, the relative preservation of coughing and swallowing is further evidence against involvement of the medulla while normal sensation, especially to pinprick and temperature, excludes anterior spinal artery insufficiency to the upper cervical cord. Tetraparesis with preservation of sensation is typical of a brain stem lesion and impairment of eye closure, conjugate deviation of the eyes and spastic dysarthria all suggest a lesion of the pons and to a lesser extent, the midbrain.

Study of the blood supply of the cervical cord ${ }^{2}$ shows that the $\mathrm{C} 1-4$ segments are supplied by the anterior spinal arteries from the vertebral and other arteries which form a suboccipital anastomosis. ${ }^{3}$ The anterior spinal artery then receives from two to four large radicular arteries which, unlike other radicular arteries, join with the anterior spinal artery to supply the lower cervical spinal cord. These arteries travel with the lower cervical nerve roots. The anterior spinal artery itself supplies both sides of the cord with central arteries alternately passing to the left and to right.

There are three papers in the literature describing ischaemic complications following this operation. ${ }^{14}$ Tasker ${ }^{4}$ suggested that the two patients in his series who developed temporary postoperative hemiparesis and hemihypaesthesia respectively, did so because of ischaemia of the cord. But he misquotes Scoville to support this hypothesis (vide infra). The studies already quoted show that interruption of radicular branches on the roots of $\mathrm{C} 1-\mathrm{C} 4$ do not cause cord ischaemia at that level (but in the lower cervical cord if anywhere), nor would there be unilateral features for the anterior spinal artery supplies both sides of the cord. Tasker's cases should probably not be accepted as examples of cord ischaemia following this operation. On the other hand Sweet's patient ${ }^{5}$ developed an immediate postoperative "remarkable areflexic atrophic total paralysis of every muscle in the upper limbs". Thus the anterior horn cells of the cervical cord from C5-T1 were rendered ischaemic by interruption of radicular arteries (or artery) on the roots of C1-C3. Usually the blood supply of the lower cervical cord relies on large radicular arteries entering with the lower cervical roots and anastomosing with the anterior spinal artery. Sweet argued that such an arrangement could not have existed in his patient and that the relevant blood supply must have been interrupted when he cut the roots of $\mathrm{C} 1-\mathrm{C} 3$. Turnbull ${ }^{2}$ provides some evidence for this unusual arrangement. In one out of 43 spinal cords studied there were just two cervical anterior radicular arteries, one $0.8 \mathrm{~mm}$ diameter on the $\mathrm{C} 8$ root and the other, $0.4 \mathrm{~mm}$ diameter on the $\mathrm{C} 3$ root. In such circumstances it is conceivable that interruption of the $\mathrm{C} 3$ artery might lead to ischaemia of the lower cervical cord. Of course, if the only feeding radicular artery was at $\mathrm{C} 3$, and this was interrupted, then there would certainly be ischaemia of the lower cervical cord. Clearly the events in Sweet's patient were quite unlike the sequence reported here.

However, Scoville's case is very similar, although not identical to our patient. Table 1 compares and contrasts both cases. The mechanism seems obscure and Scoville offered no explanation. A generalised circulatory failure would cause a predominant cortical deficit with intellectual impairment and there was no recorded fall of blood pressure in either patient. Air embolism during the operation is not responsible. Could the lesion be due to interruption of a single vessel, perhaps by an embolus from a mural thrombosis in the vertebral artery? Scoville's case would suggest that this is not tenable either. At necropsy eight months after operation bilateral medullary infarction was found in areas supplied directly by both vertebral arteries as well as by both posterior inferior cerebellar arteries. It is inconceivable that these vessels were thrombosed or embolised simultaneously some hours after operation. Nor can it be argued that there was an absent or hypoplastic vertebral artery on one side for post-mortem examination in Scoville's patient showed no hypoplosia, thrombosis or embolism.

Thus it seems likely that both vertebral arteries were suddenly and simultaneously affected at some period after the operation. Moreover, the absence of thrombosis or embolism suggests that some external compression of these arteries must have occurred. It may be relevant that both these patients had persistant head deformity prior to operation. It is known that sudden rotation of the head and neck causes obstruction of the vertebral artery at the $C 1 / 2$ level on the side to which the occiput rotates. ${ }^{6}$ The vertebral artery is angulated and fixed where it leaves the foramen transversarium of $\mathrm{C} 2$. It is also fixed where it penetrates the dura to enter the cranial 
Table 1 Comparison of Scoville's case and the Oxford case

\begin{tabular}{|c|c|c|}
\hline \multirow[t]{2}{*}{ Preoperative state } & Scoville's case & Oxford case \\
\hline & $\begin{array}{l}\text { Persistent extreme rotation } \\
\text { of chin to right }\end{array}$ & Persistent rotation of chin to left \\
\hline $\begin{array}{l}\text { Site of Lesion } \\
\text { Extent of lesion } \\
\text { Operative position } \\
\text { Time of onset after operation } \\
\text { Clinical features }\end{array}$ & $\begin{array}{l}\text { Medulla } \\
\text { Bilateral } \\
\text { Prone } \\
8 \text { hours } \\
\text { Apnoea } \\
\text { Swallowing and coughing } \\
\text { impaired }\end{array}$ & $\begin{array}{l}\text { Pons } \\
\text { Bilateral } \\
\text { Sitting } \\
1 \text { hour } \\
\text { Tetraparesis, disordered eye } \\
\text { movements, no apnoea, swallow } \\
\text { and cough intact }\end{array}$ \\
\hline $\begin{array}{l}\text { Upper cervical cord } \\
\text { Vertebral and basilar arteries }\end{array}$ & $\begin{array}{l}\text { Normal at necropsy } \\
\text { Normal at necropsy }\end{array}$ & $\begin{array}{l}\text { Clinically normal } \\
\text { Not known }\end{array}$ \\
\hline
\end{tabular}

cavity. Possibly a slowly developing, but persistent, rotation of the head might stretch this segment of the vertebral artery causing it to become elongated and narrowed, although still patient. Conversely the same segment of the opposite vertebral artery may become less mobile and flexible with such persistent shortening. Following successful operation the head and neck is then able to be straightened and indeed rotated to the opposite side. It is conceivable that the vertebral arteries are less able to compensate for such a sudden and unaccustomed movement. The previously stretched segment becomes redundant which might then kink and obstruct flow. At the same time the opposite, less flexible, segment of vertebral artery may be less able to adapt to the sudden movement towards the opposite side and becomes obstructed more easily and completely than is usually the case with such a movement. Thus it seems

Table 2 Five recent series

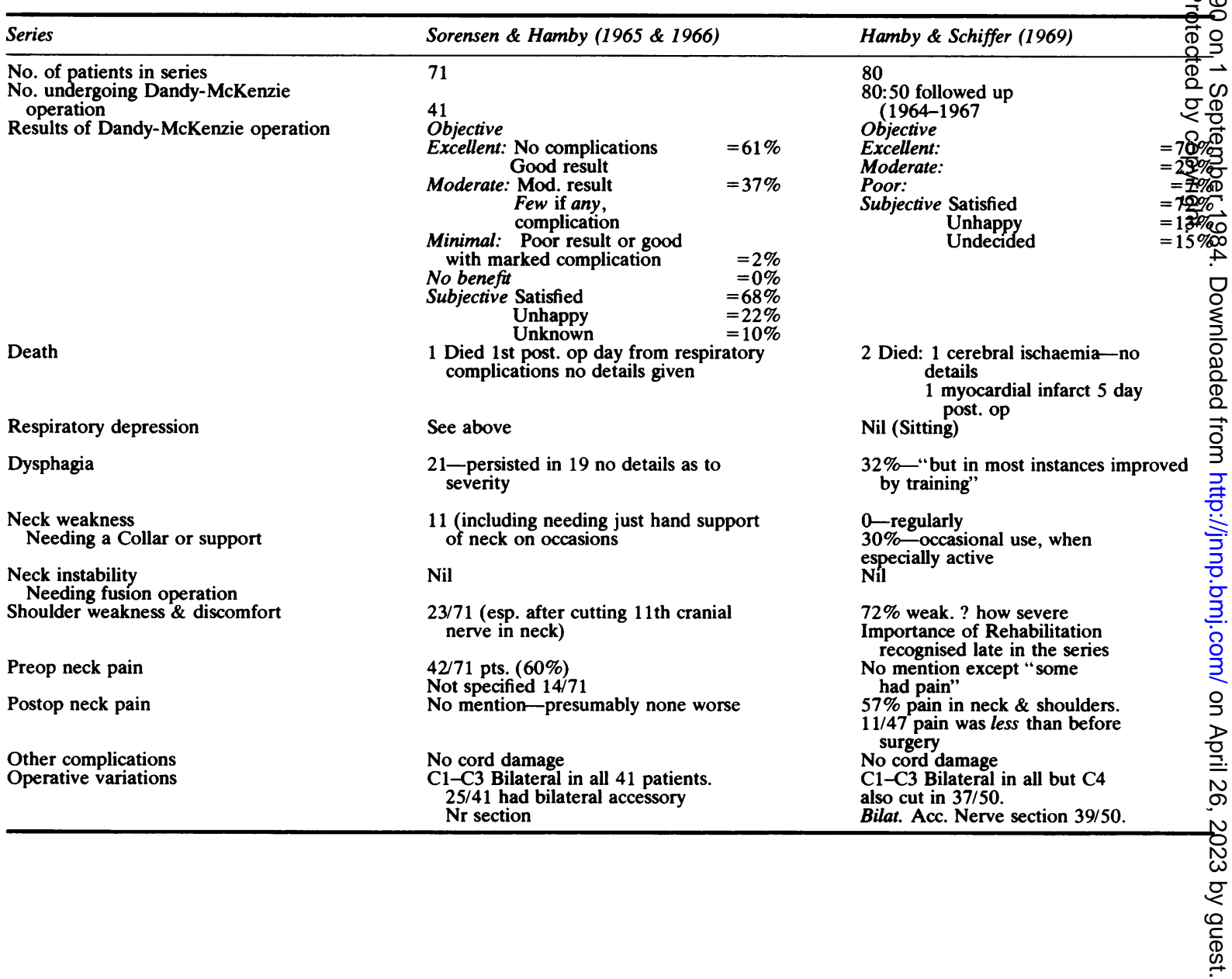


possible that sudden unaccustomed rotation to the opposite side might produce bilateral vertebral artery insufficiency. Such a theory would explain the delayed onset when the patients head was turned to the opposite side for the first time, the bilateral ischaemia, the occurrance in only those rare patients with persistent deviation of the head and the lack of thrombosis or embolism at necropsy. Perhaps the emphasis on the pons and sparing of the medulla in our patient was due to insufficient colateral blood supply to the basilar artery via the posterior communicating arteries.

This speculation is not devoid of practical importance for, if it is correct, then particular care should be taken with those patients with persistent deviation of the head. After operation these patients should be immobilised in a collar fashioned prior to operation so as to maintain the preoperative posture in the postoperative period. After 48 hours or so when the patient is alert and co-operative the head and neck can be straightened while the patient is carefully observed. Particular care is taken to avoid rota- tion of the head in the opposite direction to that produced by the previous persistent torticollis. This complication, although most unusual, may not be as rare as the literature suggests. Scoville ${ }^{1}$ on retrospective review of his cases found one further patient who had suffered a mild and temporary episode of brain stem ischaemia.

This patient precipitated further consideration as to whether or not the Dandy ${ }^{7}$ McKenzie $^{8}$ operation should be advised at all. Of course, the concept of damping down the movements without altering the underlying pathophysiology is unsatisfactory to surgeon and patient alike. The patient must understand the inevitable postoperative weakness of the neck and shoulder girdle. Postoperative physiotherapy is essential. There seems no advantage to cutting both $\mathrm{C} 4$ roots, and indeed this seems to cause greater instability of the cervical spine as well as occasional respiratory complications. ${ }^{4}$ Bilateral sectioning of the spinal accessory nerves intrathecally is associated with swallowing difficulty presumably due to weakness of the necessary reflex

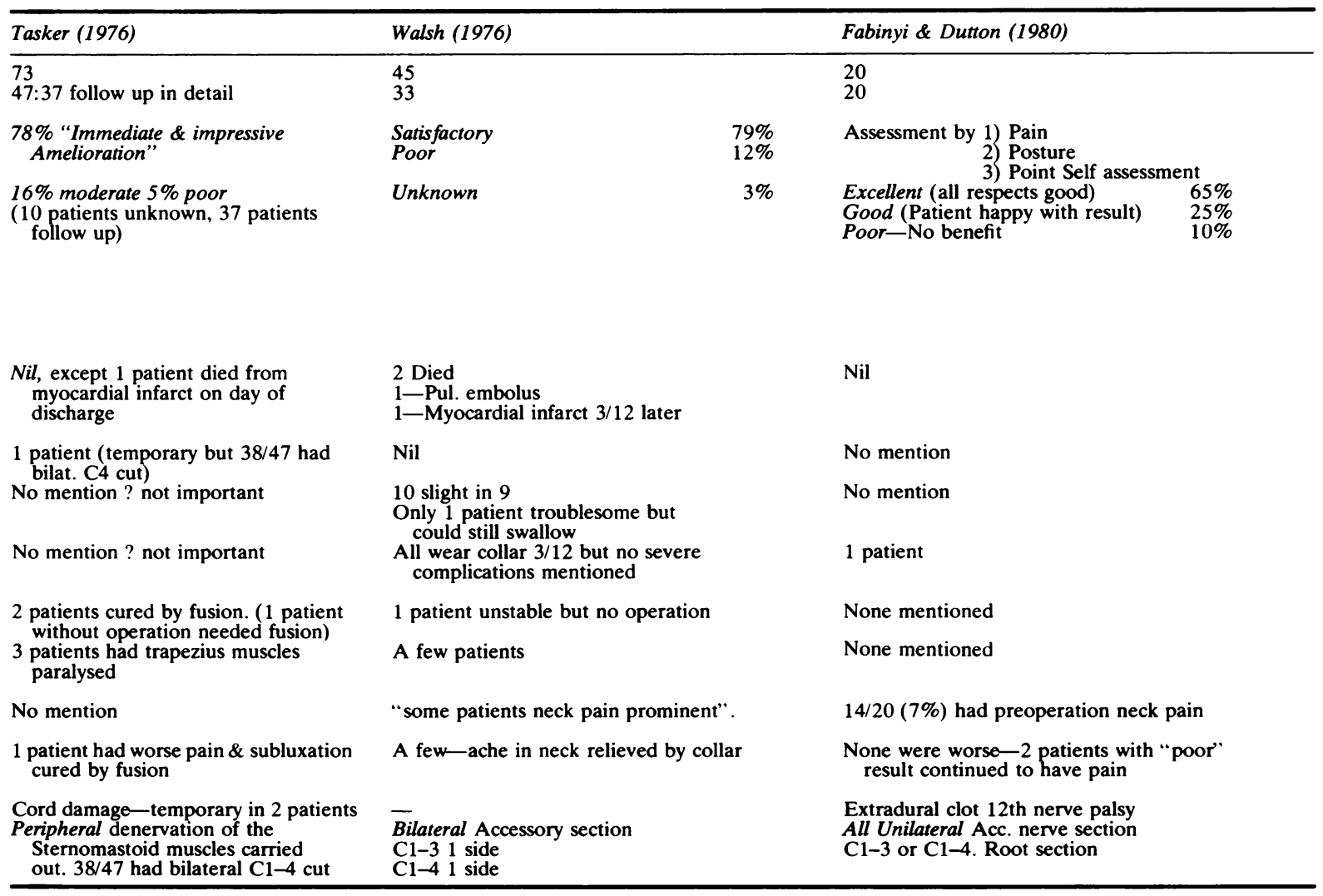


extension of the head and neck from denervation of the upper fibres of both trapezei. Unilateral intrathecal section does not cause dysphagia and if bilateral denervation is necessary, then peripheral devervation of the other sternomastoid muscles should be considered so as to allow preservation of the nerve supply to the trapezius muscle on that side.

It should be understood that there are many variation to the Dandy McKenzie operation and the exact procedure should be clearly understood when comparison is made between the various series. Table two summarises the five most recent sizeable series $^{9-13}$ and it will be seen that the operation is safe and effective with few complications other than the inevitable side effects. These can be minimised by careful patient selection (with the patient "earning" the operation rather than receiving it too early) and with proper postoperative rehabilitation. It is suggested that those rare patients with persistent deviation should be managed in the way described in this paper in the hope that further catastrophies can be avoided.

I thank Mr John Potter for permission to report this case.

\section{References}

' Scoville, WB, Bettis OB. Motor tics of the head and neck: surgical approaches and their complications. Acta Neurochir (Weir) 1979;48:47-66.

${ }^{2}$ Turnbull, IA, Brieg A, Hassler O. Blood supply of cervical spinal cord in Man. J Neurosurg 1966;24:951-65.

${ }^{3}$ Lazorthes G. Spinal angiomas. In: Advances in Diagnosis and Therapy. Pia HW, Djindjian R, eds. Berlin: Springer Verlag, 1978:1-17.

${ }^{4}$ Tasker RR. The treatment of spasmodic torticollis by peripheral devervation: the McKenzie operation. In: Current controversies in Neurosurgery. Morley TP, ed. Philadelphia: Saunders, 1976:448-54.

s Sweet, WH. What should the neurosurgeon do when faced with a malpractice suit? Clin Neurosurg 1975;23:112-24.

${ }^{6}$ Brain Lord. Some unsolved problems of cervical spondylosis. Br Med J 1963;1:771-7.

${ }^{7}$ Dandy WE. An operation for the treatment of spasmodic torticollis. Arch Surg 1930;20:1021-32.

${ }^{8}$ McKenzie KG. The surgical treatment of spasmodic torticollis. Clin Neurosurg 1955;12:37-42.

'Sorenson BF, Hamby WB. Spasmodic torticollis. Results in 71 surgically treated patients. JAMA 1965; 194: 116-8.

${ }^{10}$ Sorenson BF, Hamby WB. Spasmodic torticollis. Results in 71 surgically treated patients. Neurology (Minneap) 1966; 16:867-78.

"Hamby WB, Schiffer S. Spasmodic torticollis: results after cervical rhizotomy is 50 cases. $J$ Neurosurg 1969;31:323-6.

12 Walsh LS. Spasmodic torticollis. Inst Neurol Madras Proc 1976;6:36-41.

${ }^{13}$ Fabinyi G, Dutton J. The surgical treatment of spasmodic torticollis. Aus NZ J Surg 1980;50:155-7. 